\title{
Constraints of the durability of inorganic and organic consolidants for marble
}

\author{
Johanna Menningen $^{1} \cdot$ Enrico Sassoni $^{2} \cdot$ Robert Sobott $^{3} \cdot$ Siegfried Siegesmund $^{1}$
}

Received: 28 February 2021 / Accepted: 19 April 2021 / Published online: 6 May 2021

(c) The Author(s) 2021

\begin{abstract}
In the present study, 5 different consolidants were tested on 5 different marble varieties preliminarily subjected to artificial weathering, to evaluate their consolidating effectiveness and thermal behavior after consolidation, in terms of residual strain after heating-cooling cycles in dry and wet condition and tendency to bowing. Treatments based on ethyl silicate, with and without a coupling agent to improve the performance on calcitic substrates, exhibited modest increases in cohesion after consolidation, as well as an increase in the thermal expansion coefficient and some residual strain at the end of the cycles. Paraloid B72 caused minor alterations in the pore system and limited increases in ultrasonic velocity, while the so-called "acrylic total impregnation" method led to an almost complete pore filling and significant improvements in cohesion. While the latter samples apparently resisted well to heating-cooling cycles, samples impregnated with Paraloid B72 exhibited progressive collapse of the fabric, likely due to the low glass transition temperature of Paraloid B72. Ammonium phosphate proved to be able to significantly improve marble cohesion and led to lower residual strain after heating-cooling cycles, compared to untreated marble. The DAP-treatment also exhibited a significant ability to slow down further bowing of already bowed slabs and to prevent bowing of initially planar slabs.
\end{abstract}

Keywords Marble $\cdot$ Consolidation $\cdot$ Ethyl silicate $\cdot$ Polymethyl methacrylate $\cdot$ Thermal expansion coefficient $\cdot$ Thermal weathering $\cdot$ Residual strain $\cdot$ Bowing $\cdot$ Hydroxyapatite

\section{Introduction}

Marble sculptures and architectural elements exposed outdoors are subject to severe decay, owing to several deterioration processes such as thermal weathering, dissolution due to rainwater and pollutant deposition (Figs. 1, 2, 3).

To re-establish the cohesion among calcite grains, the use of consolidants is necessary. This is often the last possibility

This article is part of a Topical Collection in Environmental Earth Sciences on "Building Stones and Geomaterials through History and Environments-from Quarry to Heritage. Insights of the Conditioning Factors", guest edited by Siegfried Siegesmund, Luís Manuel Oliveira Sousa, and Rubén Alfonso López-Doncel.

Siegfried Siegesmund

ssieges@gwdg.de

1 Geoscience Centre of the Georg August University Göttingen, Göttingen, Germany

2 Department of Civil, Chemical, Environmental and Materials Engineering, University of Bologna, Bologna, Italy

3 Labor für Baudenkmalpflege, Naumburg, Germany to prevent further reduction in strength, which may possibly lead to a collapse of the marble element. The aim of stone consolidation is to increase the strength of the weathered surface parts of a stone, which should reach a condition as close as possible to that of the unweathered core, thus achieving a uniform strength profile with depth. The consolidant should not cause over-strengthening of the stone surface but should penetrate to the sound core, where the strengthening effect should gently fade away (Snethlage 2008). Generally, the consolidant should stick to the grain or crystal surfaces to exert a bond between them. The filling of wider pores and cracks requires a high concentration of the active component in the solution and the density difference between the solution and the solid reaction product should be as low as possible.

Within the scope of the Eureka Project EU 496 Eurocare Euromarble from 1990 to 1999 all aspects pertaining to the weathering and conservation of marble were treated and the result was a very significant increase in knowledge about the weathering mechanisms and conservation methods and chemicals. A comprehensive overview about the historical 


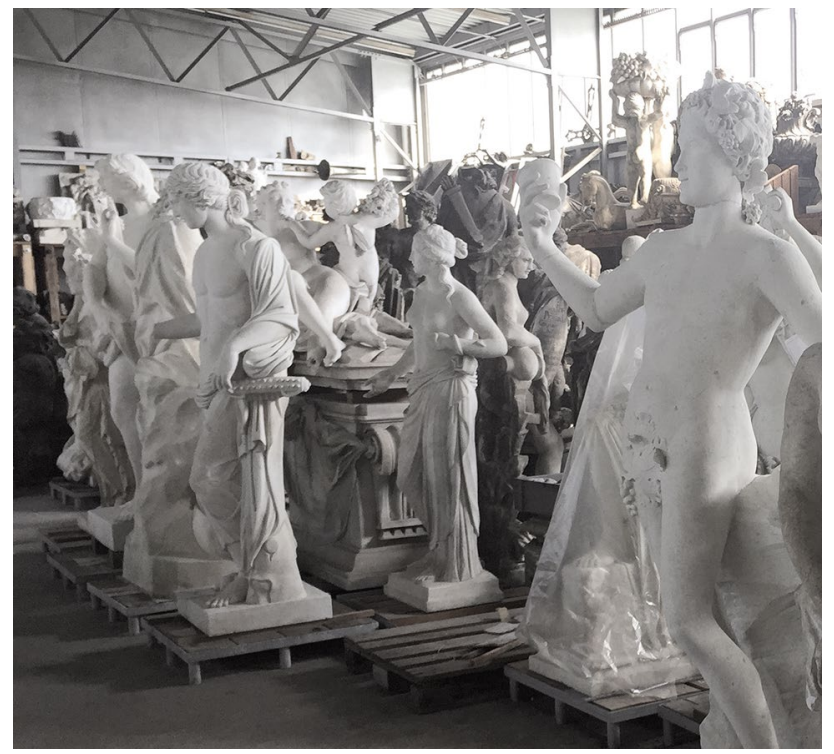

Fig. 1 Storage of fragile sculptures to protect them from ongoing decay, as here in the Sculpture Hall of the Prussian Palaces and Gardens Foundation

development of materials and methods for marble conservation has been reported by Simon (2001).

For stone consolidation to be successful, various parameters have to be considered, to ensure the effectiveness, compatibility and durability of the intervention. Several authors (e.g. Delgado and Grossi 2007; Snethlage 2008) have proposed catalogues of requirements that consolidants should meet. They built reference criteria to assess their suitability, by defining a framework for an acceptable deviation of the strengthened stone properties, compared to the unweathered ones.

In the specific case of marble consolidation, a very important aspect that needs to be thoroughly evaluated is the thermal behavior of marble after treatment with a consolidant. In fact, some consolidating treatments have been found to be effective in rightly re-establishing marble cohesion after treatment, but the consolidating effect is rapidly lost when the consolidated marble is subject to thermal cycles. For instance, this was the case of marble consolidated with polymethyl-methacrylate (Ruedrich et al. 2002) or ammonium oxalate (Sassoni et al. 2018a), subjected to thermal cycles. However, with respect to the practical application of such experiments the results become questionable when the maximum temperature of the cycle exceeds the temperatures that occur in nature. Because thermal weathering is one of the main causes of deterioration of marble (Siegesmund et al. 2000), evaluating the stability of consolidated marble to heating-cooling cycles is essential, as the application of a consolidant with unsuitable thermal behavior may be even counterproductive, as it may accelerate marble deterioration by increasing its sensitivity to thermal cycles (Sassoni et al. 2018a).

The present study is aimed at evaluating the consolidating effectiveness and the thermal behavior of 5 different consolidants, tested on 5 different marble varieties. The investigated consolidants include 2 treatments based on ethyl silicate, 2 treatments based on acrylic resin and 1 treatment based on ammonium phosphate.

Ethyl silicate, which has high consolidating effectiveness when applied on silicate stones, is often used to consolidate also carbonate stones, even though its effectiveness is known
Fig. 2 Monuments of General von Bülow and General von Scharnhorst, sheltering of both monuments at their current location during the winter time to avoid extreme climate condition and its effect on the progressing decay (after Menningen et al. 2020)

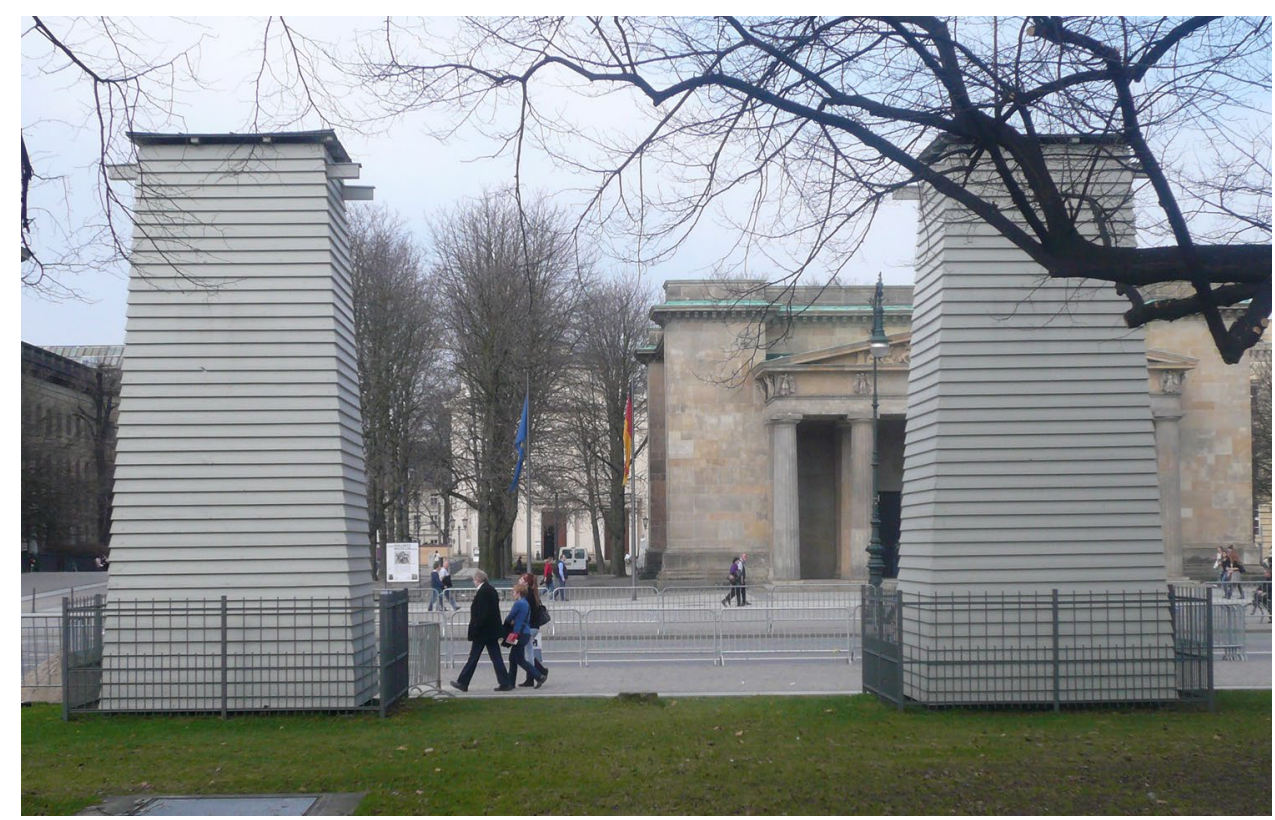


Fig. 3 Examples of marble artifacts subject to black crust formation (a), bowing (b), back weathering and cracking (c) and microscope images of marble affected by crack formation at grain boundaries (d) and surface etching (e)
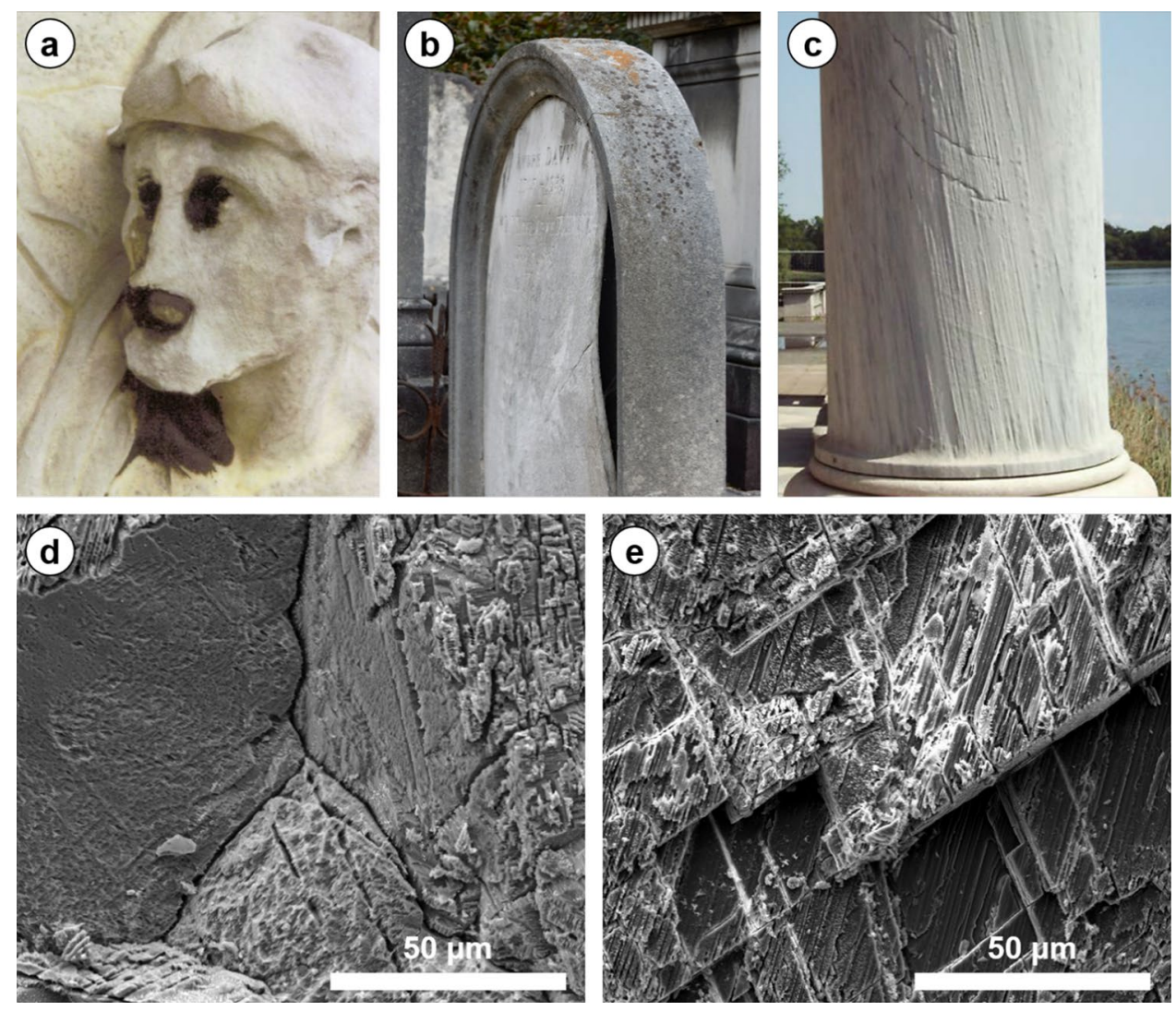

to be limited on this kind of substrate, because of the lack of chemical bonding to calcite (Wheeler 2005). Nonetheless, ethyl silicate is often used because its low viscosity allows for deep penetration into weathered marble and because the formation of silica gel in the fissures among calcite grains is able to limit grain loss, although mechanical properties are not significantly improved (Wheeler 2005; Scherer and Wheeler 2009). To overcome this limitation, innovative formulations containing so-called coupling agents, aimed at allowing for chemical bonding between the silica gel and the calcitic substrate, have been developed. In the present study, two commercial products, with and without coupling agent, were tested.

Acrylic polymers used in stone conservation are prepolymerized polymethyl methacrylates (PMMA), which are dissolved in a solvent and dry physically by evaporation of the solvent. The properties of these polymethacrylates (e.g. the glass transition temperature) can be adjusted by adding co-polymers. Treatments based on acrylic resins have been used for stone consolidation for decades, because of their effectiveness in bonding calcite grains and their capability to provide also water-repellent properties, even though their sensitivity to photo-oxidative weathering is a known major issue (Favaro et al. 2006). In the present study, two treatments based on acrylic resin were considered, namely Paraloid B72 (a mixture of methyl methacrylate and ethyl methacrylate) and the so-called "Acrylic Total Impregnation" (ATI, a method developed by Jbach GmbH, www. ibach.eu). The ATI method is based on the saturation of the pore space by methyl methacrylate that polymerizes under the application of heat and pressure. This method has been used to preserve important sculptures and monuments showing strong granular disintegration, such as the marble sculptures in the Park Sanssouci, Potsdam. Recently, the ATI method has been further modified and improved (Sobott et al. 2019), resulting in a higher glass transition temperature of $80-85^{\circ} \mathrm{C}$ and a lower thermal load for the stone during the ATI.

The use of inorganic solutions of disodium hydrogen phosphate to reduce calcite dissolution, with potential protective action on marble surfaces, was reported by Koutsoukos (1995). The effectiveness of aqueous solutions of diammonium hydrogen phosphate for the consolidation of limestone (Sassoni et al. 2011) and protection of marble (Naidu et al. 2011) was first reported in 2011. Afterwards, several studies have explored the potential of ammonium phosphate for consolidation of sandstones (Sassoni et al. 2013), marble (Sassoni et al. 2015, 2018b), gypsum (Sassoni et al. 2018c) and mortars (Sassoni and Franzoni 2020). A recent study has shown that ammonium phosphate solutions are able to mitigate marble thermal weathering, by reducing the residual strain after heating-cooling cycles and by 
reducing the tendency of thin marble slabs to bow (Sassoni et al. 2018a). This is notable because no commercial treatment is currently available specifically for the mitigation of marble bowing. The so-called bowing of marble slabs is a weathering phenomenon that can be observed with marble panels used as gravestones, commemorative stones and panels used to clad building façades. It is originated by temperature gradients across the slab thickness and is enhanced by environmental parameters (e.g. presence of moisture in pores and cracks) and intrinsic marble properties (e.g. chemical composition and lattice preferred orientation) (Siegesmund et al. 2008; Koch and Siegesmund 2004). Bowing can be so extreme to lead to panel fracturing and collapse, so the result of this phenomenon is frequently the precautionary removal and replacement of bowed panels, with significant economic implications.

Considering that the thermal behavior of marble treated with organic or inorganic consolidants has been specifically assessed only in a limited number of studies (Ruedrich et al. 2002; Sassoni et al. 2017, 2018a) and also considering that the promising ability of ammonium phosphate to reduce bowing has been assessed in a single study only (Sassoni et al. 2018a), the present work had the twofold aim of (i) evaluating the effectiveness of 5 alternative consolidants on several marble varieties and specifically assessing the thermal behavior of the consolidated marbles when subjected to heating-cooling cycles; (ii) verifying the ability of ammonium phosphate to mitigate bowing, by testing the treatment on different marble varieties with different fabric properties.

\section{Marble varieties}

Five different types of calcitic marble were considered: Blanco Macael (BM), Großkunzendorf (GK), Lasa (LA) and Carrara Gioia (GI). Moreover, a slab removed from the University of Göttingen Library (SUB), identified as Bianco Carrara Gioia Venato (Siegesmund et al. 2008), was used as a naturally bowed substrate for testing the ability of ammonium phosphate to reduce bowing.

The various marble types, the respective acronym, description of their grain fabric, average grain size and texture are reported in Table 1. Except for GK, all marble varieties have a granoblastic grain fabric with straight grain boundaries and medium grain sizes between 284 and $485 \mu \mathrm{m}$. The GK has a seriate-interlobate grain fabric with interlocking grain boundaries and an average grain size of $545 \mu \mathrm{m}$, the largest among all the five varieties. Except for LA, all marbles show typical c-axis maxima, described as c-axis fibre type (Leiss and Ullemeyer 1999) with low (SUB) to high (BM) intensities. The c-axes of LA are almost girdle like arranged as an a-axes fibre type.
All samples used for the experimental tests were cut from one single block per variety. Different types of specimens were prepared: (i) for all the consolidants, cylinders (diameter $=15 \mathrm{~mm}$, height $=50 \mathrm{~mm}$ ) were used to assess the treatment effectiveness and to test the thermal expansion after consolidation (Koch and Siegesmund, 2004); (ii) for the treatments based on ethyl silicate and acrylic resin, cubes ( $65 \mathrm{~mm}$ side) were also used to evaluate the treatment effectiveness and the alterations in effective porosity; (iii) in the case of ammonium phosphate, prismatic specimens (length $=400 \mathrm{~mm}$, width $=100 \mathrm{~mm}$, thickness $=30 \mathrm{~mm}$ ) were used to test the bowing behavior according to the European Standard EN 16,306. In the case of the SUB specimens, since the removed panel had a thickness of $40 \mathrm{~mm}$, the samples obtained from this panel had the same thickness.

\section{Preliminary artificial deterioration}

Before consolidant application (Fig. 4a), cylinders and cubes were artificially aged by repetitive heating. The cylinders were heated to $200{ }^{\circ} \mathrm{C}$, the temperature was maintained for $4 \mathrm{~h}$ and subsequently the samples were cooled down to about $4{ }^{\circ} \mathrm{C}$. This cycle was repeated 4 times. The cubes were heated up to $40{ }^{\circ} \mathrm{C}$ and then cooled down to about $4{ }^{\circ} \mathrm{C}$, afterwards the temperature was increased step wise to $60^{\circ} \mathrm{C}$, $90{ }^{\circ} \mathrm{C}, 120^{\circ} \mathrm{C}, 150{ }^{\circ} \mathrm{C}$ and finally up to $200{ }^{\circ} \mathrm{C}$, each step followed by cooling down. So these samples were treated at least 6 times with different temperatures.

To reproduce the condition of bowed slabs in the field that are consolidated to prevent further bowing, the panels were preliminarily bowed by inducing a temperature gradient across the panel thickness, by subjecting them to 65 heating-cooling cycles (Sassoni et al. 2018a). During the first 40 cycles, a maximum temperature of $90^{\circ} \mathrm{C}$ was reached, while during the last 25 cycles the maximum temperature was increased up to $120^{\circ} \mathrm{C}$ to increase the level of deterioration.

\section{Consolidation}

The following treatments were used to consolidate the different marble varieties:

(1) KSE 300: the commercial product KSE F300 by Remmers, composed of silicic acid ester, was used in undiluted form;

(2) KSE $300 \mathrm{HV}$ : the commercial product KSE $300 \mathrm{HV}$ by Remmers, also containing a coupling agent for better binding onto carbonate substrates, was used in undiluted form;

(3) Paraloid B72: a $5 \mathrm{wt} \%$ solution of the polymethylmethacrylate Paraloid B72 in Xylol was used; 
Table 1 The various marble types and description of their grain fabric, average grain size and texture

\begin{tabular}{|c|c|c|c|c|}
\hline Name & Macrofabric microfabric & Grain fabric & $\begin{array}{l}\text { Grain size } \\
(\mu \mathrm{m})\end{array}$ & Texture (mrd) \\
\hline Blanco Macael (BM) & & Equigranular-polygonal & 495 & 2.9 \\
\hline Großkunzendorf (GK) & & Seriate-interlobate & 545 & 1.58 \\
\hline Lasa (LA) &. & Equigranular-polygonal & 419 & 2.06 \\
\hline Carrara Gioia (GI) & & Equigranular-polygonal & 284 & 2.35 \\
\hline $\begin{array}{l}\text { Göttingen library (Gioia } \\
\text { Venato) (SUB) }\end{array}$ & & Equigranular-polygonal & 300 & 1.3 \\
\hline
\end{tabular}

SUB data were adapted from (Siegesmund et al. 2008)

(4) ATI: The new formulation of the Acrylic Total Impregnation (Sobott et al. 2019) method was used, namely "ATI50", which is characterized by high glass transition temperature $\left(80-85^{\circ} \mathrm{C}\right)$;
(5) DAP: An aqueous solution containing $1 \mathrm{M}$ $\mathrm{DAP}+1 \mathrm{mM} \mathrm{CaCl}{ }_{2}(\mathrm{DAP}=$ ammonium hydrogen phosphate, $\left.\left(\mathrm{NH}_{4}\right)_{2} \mathrm{HPO}_{4}\right)$ was used. This formulation, first proposed by Naidu and Scherer (2014), was 
selected based on previous studies that showed its effectiveness for marble surface protection and consolidation (Graziani et al. 2016; Sassoni et al. 2018b) and prevention of bowing (Sassoni et al. 2018a). Indeed, calcium phosphates, formed from the reaction between the DAP solution and the stone, are able to effectively bind calcite grains and increase mechanical properties, without significantly occluding the intergranular fissures. The lack of complete occlusion of the existing fissures allows for calcite grain deformation upon heating without stress at grain boundaries (Sassoni et al. 2018a, b).

Samples consolidated by treatments 1-3 were fully saturated under atmospheric conditions with the specific material and left to cure for $24 \mathrm{~h}$. Afterwards, samples 1-2 were stored in a climate chamber with $70 \%$ air humidity and $23{ }^{\circ} \mathrm{C}$, while the samples of treatment 3 were stored in a Xylol solvent-based climate for 1 week. The ATI process was carried out by the Jbach $\mathrm{GmbH}$ in Schesslitz. To achieve total impregnation, MMA was forced into the pore system of the autoclaved samples by several vacuum/ pressure cycles (Fig. 4b). After the pore-filling process, the polymerization process was triggered thermally (Wihr 1995).

DAP was applied onto the external surface of the samples with a brush until the uptake stopped. Then the samples were wrapped in a plastic film for $24 \mathrm{~h}$ to prevent evaporation. The samples were then unwrapped, rinsed with water and finally dried at room temperature until constant weight. All the samples were left to cure for a total of 6 weeks before testing.

A summary of the treatment conditions for each consolidant and each marble variety, with an indication of the types of specimens tested, is reported in Table 2.
Table 2 Summary of the treatment conditions $(\mathbf{O}=$ cylindrical specimens; $\mathbf{\square}=$ cubic specimens; $\boldsymbol{\square}=$ prismatic specimens)

\begin{tabular}{|c|c|c|c|c|c|}
\hline & BM & GK & LA & GI & SUB \\
\hline KSE 300 & 무 & 0 & 口 & 무 & - \\
\hline KSE $300 \mathrm{HV}$ & a & 口 & 口 & 口 & - \\
\hline ParaloidB72 & a & 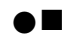 & 口 & 口 & - \\
\hline ATI & & & & 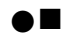 & - \\
\hline DAP & 으 & $O=$ & O & 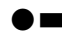 & a \\
\hline
\end{tabular}

\section{Measurement techniques}

\section{Consolidating effectiveness}

To evaluate the effects of artificial pre-deterioration, consolidation and accelerated ageing by heating-cooling cycles, the marble cohesion was assessed on cubic and cylindrical specimens by ultrasonic measurements. The ultrasonic velocity of the $\mathrm{P}$-wave $\left(V_{p}\right)$ in transmission was measured using a Geotron Elektronik instrument with $350 \mathrm{kHz}$ probes. $V_{p}$ was assumed as a reliable parameter to estimate the marble conservation state, as previous studies have shown the strong relation existing in marble between $V_{p}$, porosity, compressive and tensile strength (Weiss et al. 2002; Ruedrich et al. 2013; Menningen et al. 2018).

In total, 4 conditions were considered: (0) the preweathered condition, (I) the artificially weathered condition, (II) the consolidated condition and (III) the thermally aged condition. Since marble is known to have anisotropic properties, all analyses were performed with regard to the stone orientation, to take into account any directional dependence.
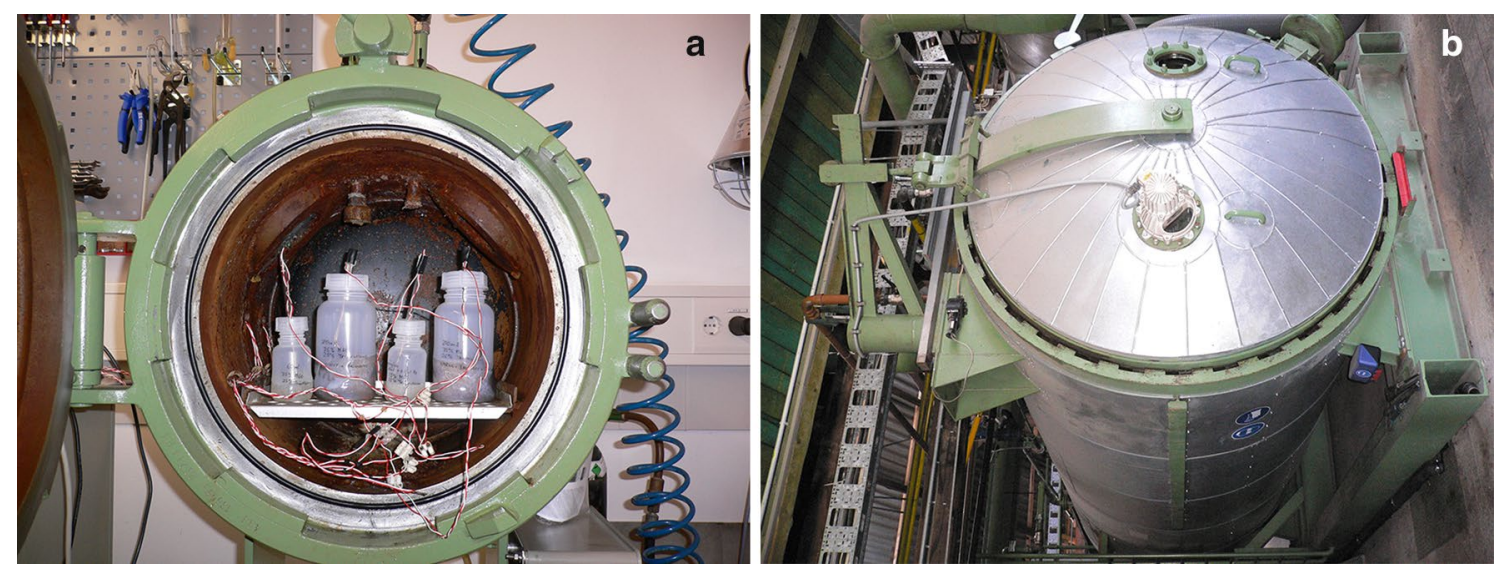

Fig. 4 a Laboratory control of the consolidants prior to the consolidant application b closed autoclave of the AVT full impregnation technology of the JBACH Steinkonservierung $\mathrm{GmbH}$ 


\section{Alteration in the pore system}

The alteration in open porosity after artificial weathering and consolidation was established for the cubic specimens according to the Standard DIN 52102 (water uptake measurements).

\section{Resistance to heating-cooling cycles}

The thermal dilation of artificially weathered, untreated and treated marbles was examined, always taking into account the directional dependency. Cylindrical specimens were subjected to heating/cooling cycles $\left(20-90-20{ }^{\circ} \mathrm{C}\right)$ under dry and wet conditions ( 3 and 5 cycles, respectively) (Koch and Siegesmund 2004). The thermal expansion coefficient $\alpha$ $\left(10^{-6} \mathrm{~K}^{-1}\right)$ after the first cycle and the residual strain $(\mathrm{mm} / \mathrm{m})$ after each cycle were registered.

\section{Resistance to bowing}

After preliminary induced bowing as described above, prebowed slabs were treated with the DAP solution and then subjected to additional 30 bowing cycles $\left(20-90-20{ }^{\circ} \mathrm{C}\right.$ under wet conditions). The treatment's ability to reduce bowing was evaluated as the change in the bowing rate, before and after consolidation. Moreover, one unweathered slab was DAP-treated and subjected to the same cycles, to evaluate the treatment's ability to prevent bowing. Bowing (in $\mathrm{mm} / \mathrm{m}$ ) was measured every 10 cycles by using a gauge with $0.5 \mu \mathrm{m}$ accuracy and a metal frame to ensure the measurement's repeatability.

\section{Results and discussion}

\section{Consolidating effectiveness}

The changes of the ultrasonic velocity $\left(V_{p}\right)$ in the marble samples after artificial weathering by heating and after consolidation are illustrated in Fig. 5 for cubic specimens and Fig. 6 for cylindrical specimens.

Artificial weathering caused a general decrease in $V_{p}$ for all the marble varieties, as a consequence of the formation of new microcracks at the grain boundaries caused by heating.

After consolidation, all the treatments led to an increase in $V_{p}$ in both the cubes and the cylinders, the benefit resulting generally higher in the latter specimens. In fact, for a given penetration depth of a consolidant, the smaller the specimen size, the higher the consolidating effectiveness registered by ultrasounds.

KSE 300 caused modest increases in $V_{p}$, especially in the case of the cubes, which can be explained considering the lack of chemical bonds to the substrate. The KSE 300 $\mathrm{HV}$ formulation, containing a coupling agent to improve the binding to calcitic substrates, caused slightly higher increases in $V_{p}$. However, with a few exceptions, the
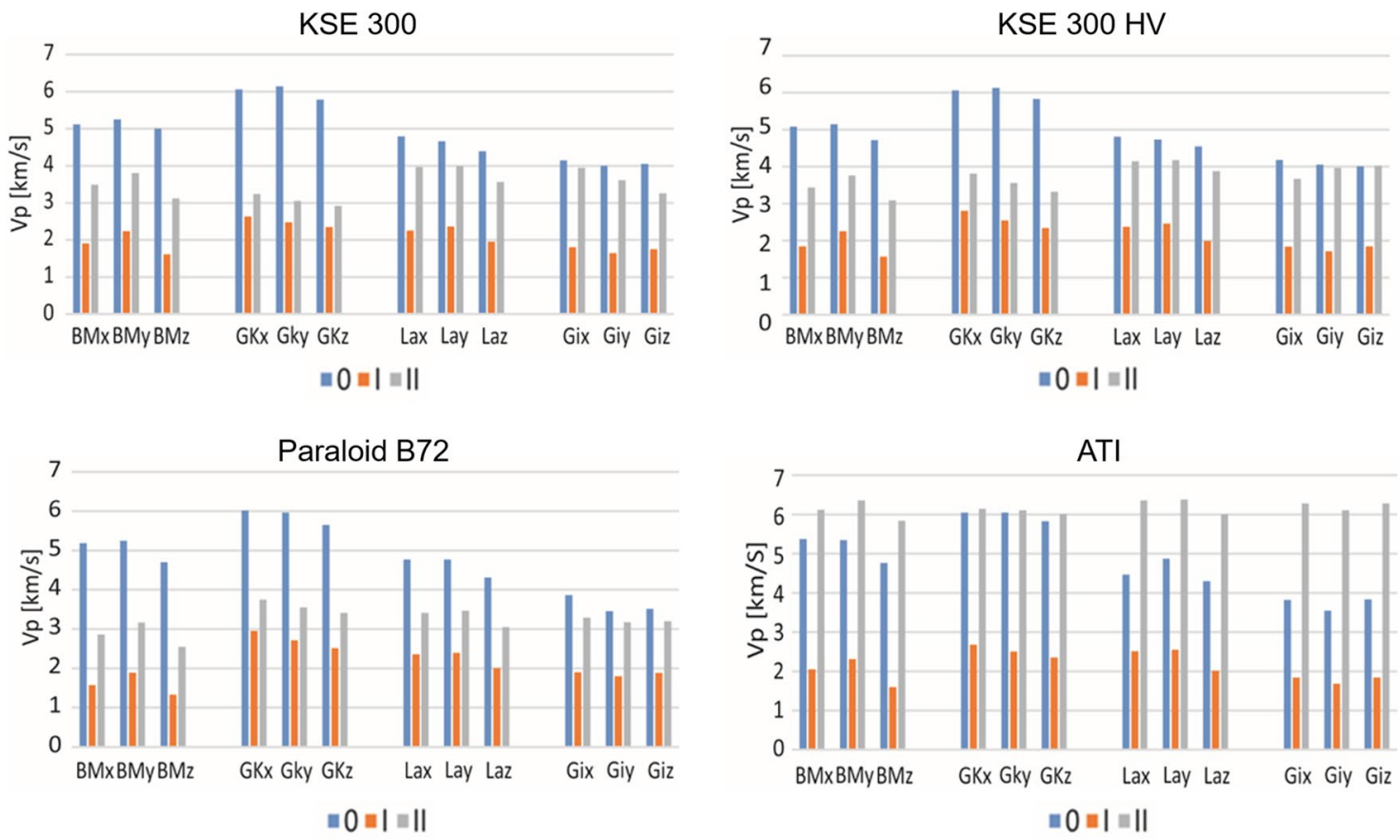

Fig. 5 Ultrasonic velocities [km/s] determined for the marble varieties Blanco Macael (BM), Großkunzendorfer (GK), Lasa (LA) and Gioia (GI) in the unweathered state (blue bars (0)), the weathered state (orange bars (I)) and after consolidation by the various treatments (grey bars, II) 

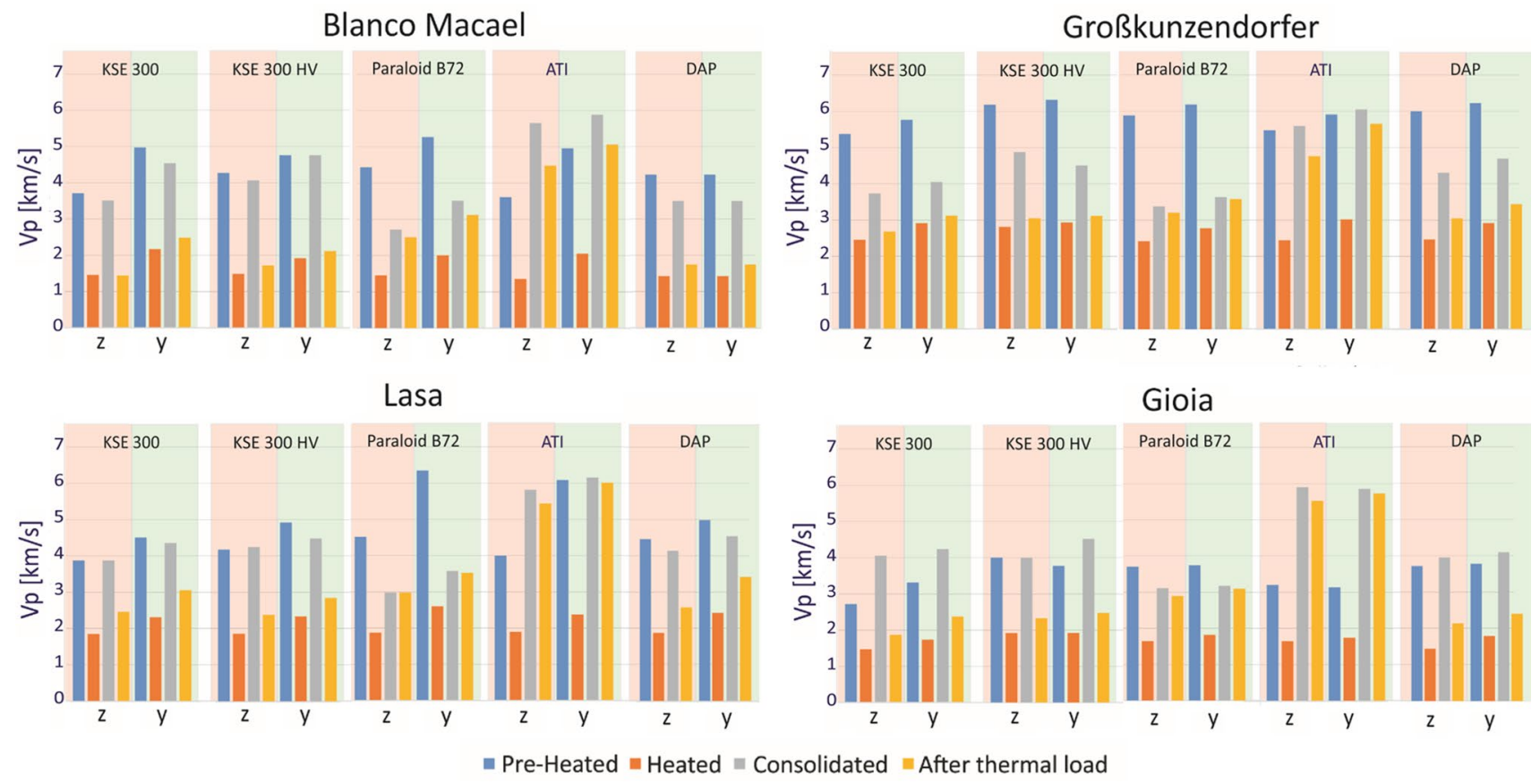

Fig. 6 Ultrasonic velocities $[\mathrm{km} / \mathrm{s}]$ determined for the marble varieties Blanco Macael (BM), Großkunzendorfer (GK), Lasa (LA) and Gioia (GI) in the unweathered state (blue bars), the weathered state

treatment was not able to restore the $V_{p}$ to the level before artificial weathering.

The application of Paraloid B72 caused only little increases in $V_{p}$, which made this treatment the least effective consolidating agent. The acrylic total impregnation (ATI) was able to restore the $V_{p}$ to the level of quarry fresh marble and even to higher values, due to the deep penetration of the consolidant into weathered marble and the deposition of PMMA in intergranular fissures.

The application of the DAP solution led to significant increases in the cohesion of all specimens, in some cases (but not all) reaching the condition of unweathered marble. This was possible as the DAP treatment caused the formation of new calcium phosphates at the grain boundaries, which are able to bind the grains more effectively and to increase mechanical properties (Sassoni 2018).

\section{Alteration in the pore system}

The changes in effective porosity after artificial weathering and consolidation are illustrated in Fig. 7.

Artificial weathering by heating was responsible for dramatic increases in porosity in all marble varieties, in agreement with the observed decreases in $V_{p}$ for all the specimens after artificial weathering (Figs. 5 and 6). (orange bars) after the consolidation (grey bars) and after additional thermal load (yellow bars)

Both consolidants, KSE 300 and KSE $300 \mathrm{HV}$, caused slight reductions in porosity. These reductions are owing to the deposition of silica gel in the pores and fissures between/ in grains. Paraloid B72 caused very modest changes in porosity, likely because of the reduced depth of penetration of the consolidant into the marbles. This is consistent with the limited increases in $\mathrm{V}_{\mathrm{p}}$ detected after treatment with Paraloid B72 (Figs. 5 and 6). Differently, the ATI treatment had the biggest impact on the porosity system. The effective porosity was reduced to the level of unweathered marble and to even lower values, because of the complete pore filling with PMMA. This is consistent with the ultrasonic results, as ATI induced the highest increases in $V_{p}$.

In the case of the DAP treatment, porosity measurements were not performed, as previous studies showed that only minor alterations in open porosity and pore size distribution are experienced after treatment (Sassoni et al. 2018a; Sassoni 2018).

Modest changes in the pore system may be considered as a positive feature of a consolidating treatment, because a strong reduction in open porosity, although linked to a high consolidating effectiveness, may actually increase marble susceptibility to thermal stress (Sassoni et al. 2018a). In fact, in case pores are completely occluded by a rigid compound after consolidation, calcite crystal deformation upon heating is expected to lead to stress at grain boundaries and consequent microcrack formation. In 

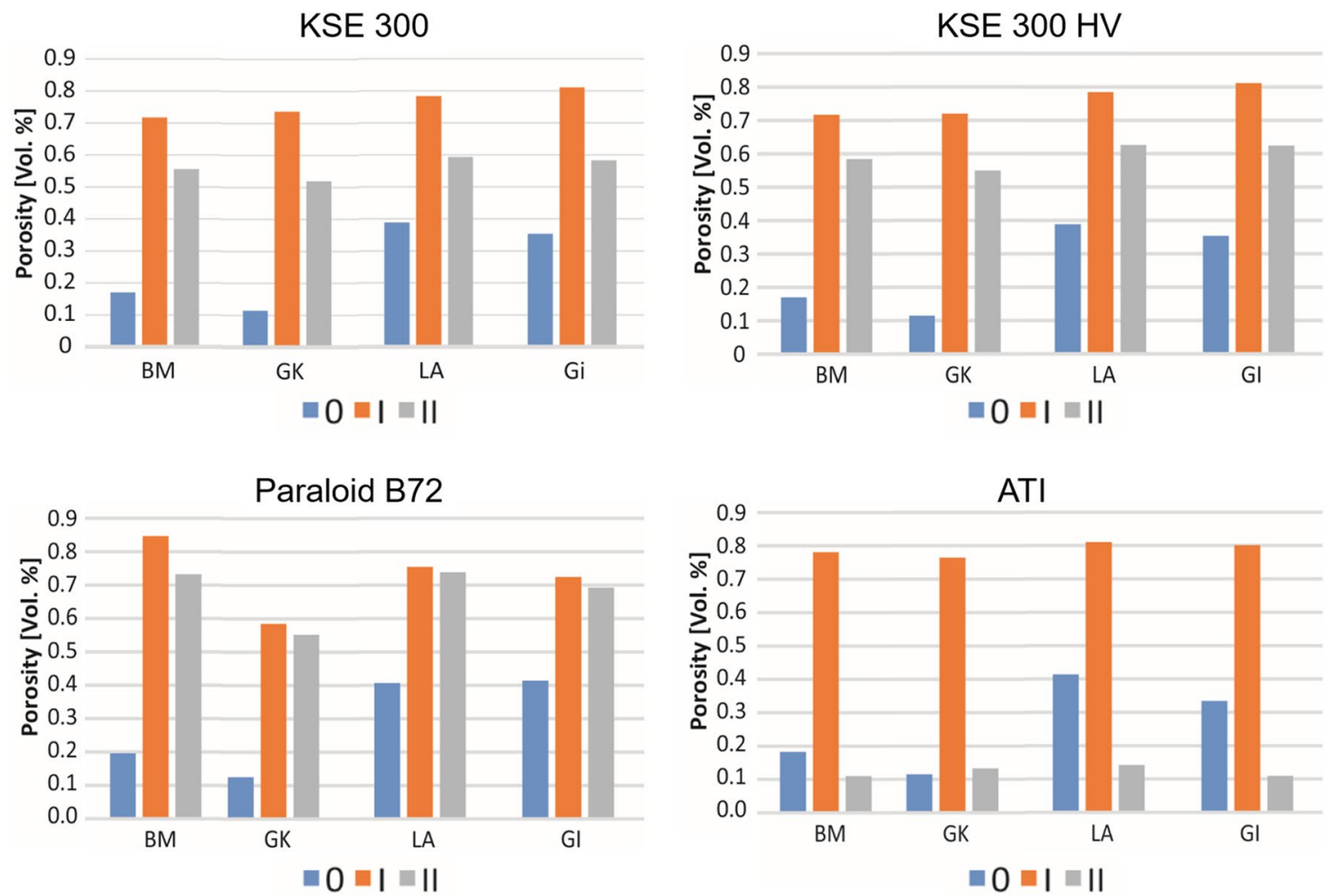

Fig. 7 Effective porosity (vol \%) of unweathered (blue bars, 0), weathered (orange bars, I) and consolidated (grey bars, II) samples of the different marble varieties

contrast, when voids are present among grains, the deformation of calcite crystals may be accommodated in the intergranular spaces, so that deformation caused by temperature variations can take place without stress at grain boundaries and microcrack formation, at least to a certain extent. Limited stress is also expected if the intergranular spaces are filled with a deformable consolidant, like in the case of acrylic resin, so that calcite crystal deformation can occur because the resin can easily follow and accommodate the crystal deformation.

\section{Effects of heating-cooling cycles}

For all the treatments, the thermal expansion coefficient $\alpha$ of untreated and consolidated marbles is reported in Table 3, in the directions of highest (Z) and lowest (X) expansion. Exemplary hysteresis curves for Blanco Macael and Gioia are shown in Figs. 8 and 9, respectively.

For all marble varieties, the KSE 300 and KSE $300 \mathrm{HV}$ treatments caused an increase in the thermal expansion coefficient with respect to the untreated marble, especially in the direction of the highest expansion. This is potentially

Table 3 Thermal expansion coefficient $\alpha\left(10^{-6} \mathrm{~K}^{-1}\right)$ of untreated and consolidated marble varieties in the X-and Z-direction

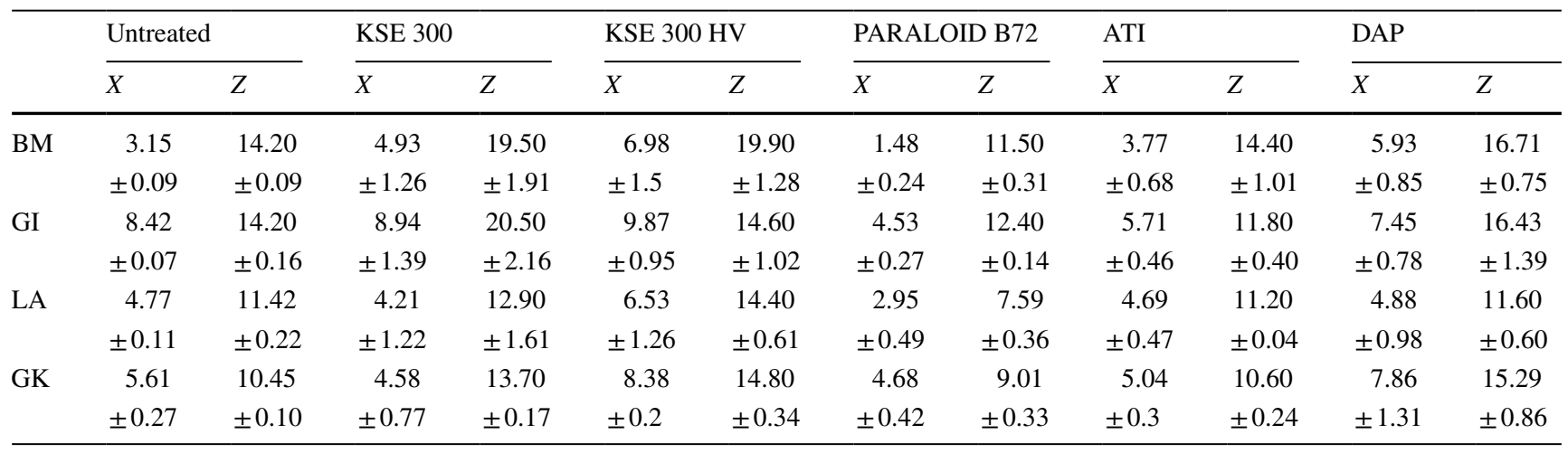



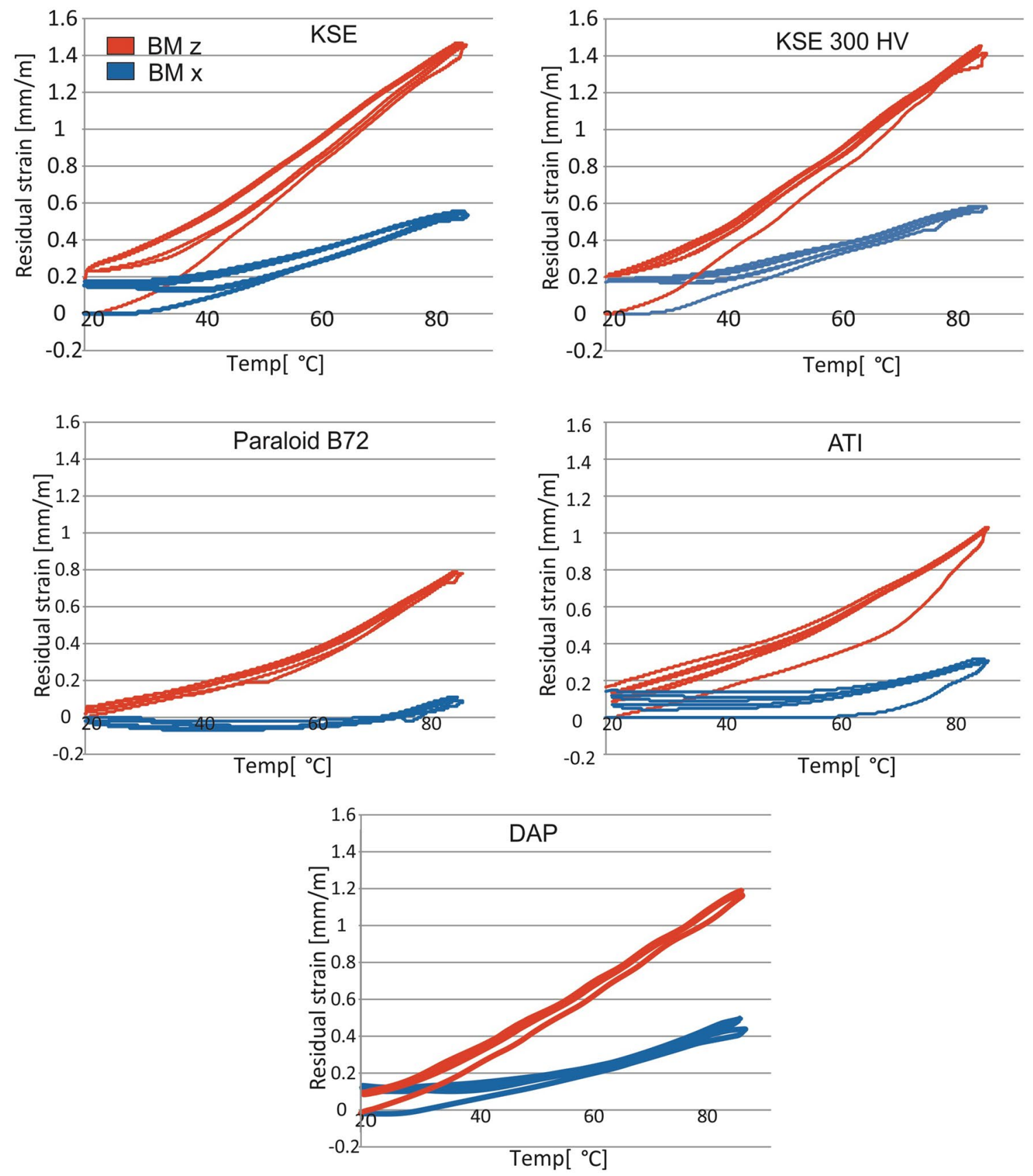

Fig. 8 Thermal dilatation $\varepsilon(\mathrm{mm} / \mathrm{m})$ shown as a loop of hysteresis for the Z-and X-direction of the Blanco Macael, treated with the different consolidants

problematic, as the higher the expansion upon heating, the higher the risk that calcite grain deformation induces stress at grain boundaries. After the first heating-cooling cycle, a residual strain was registered (Figs. 8 and 9), while the following cycles led to straighter hysteresis curves and lower residual strain at the end of the cycle.

Paraloid B72 caused a decrease in thermal expansion coefficient in all the marble varieties, compared to the untreated condition, as well as very limited residual strain after the cycles. The ATI treatment caused almost no change in the thermal expansion coefficient and limited residual strain. The slope of expansion registered for the ATI and Paraloid B72 treatments applied to the Blanco Macael and the Carrara Gioia exhibits an interesting behavior, which at first sight could be correlated to the glass transition temperature $\left(T_{g}\right)$ of the two consolidants. Both treatments show a low increase of the slope until the samples treated with Paraloid B72 reach about $50{ }^{\circ} \mathrm{C}$ and the samples treated with 

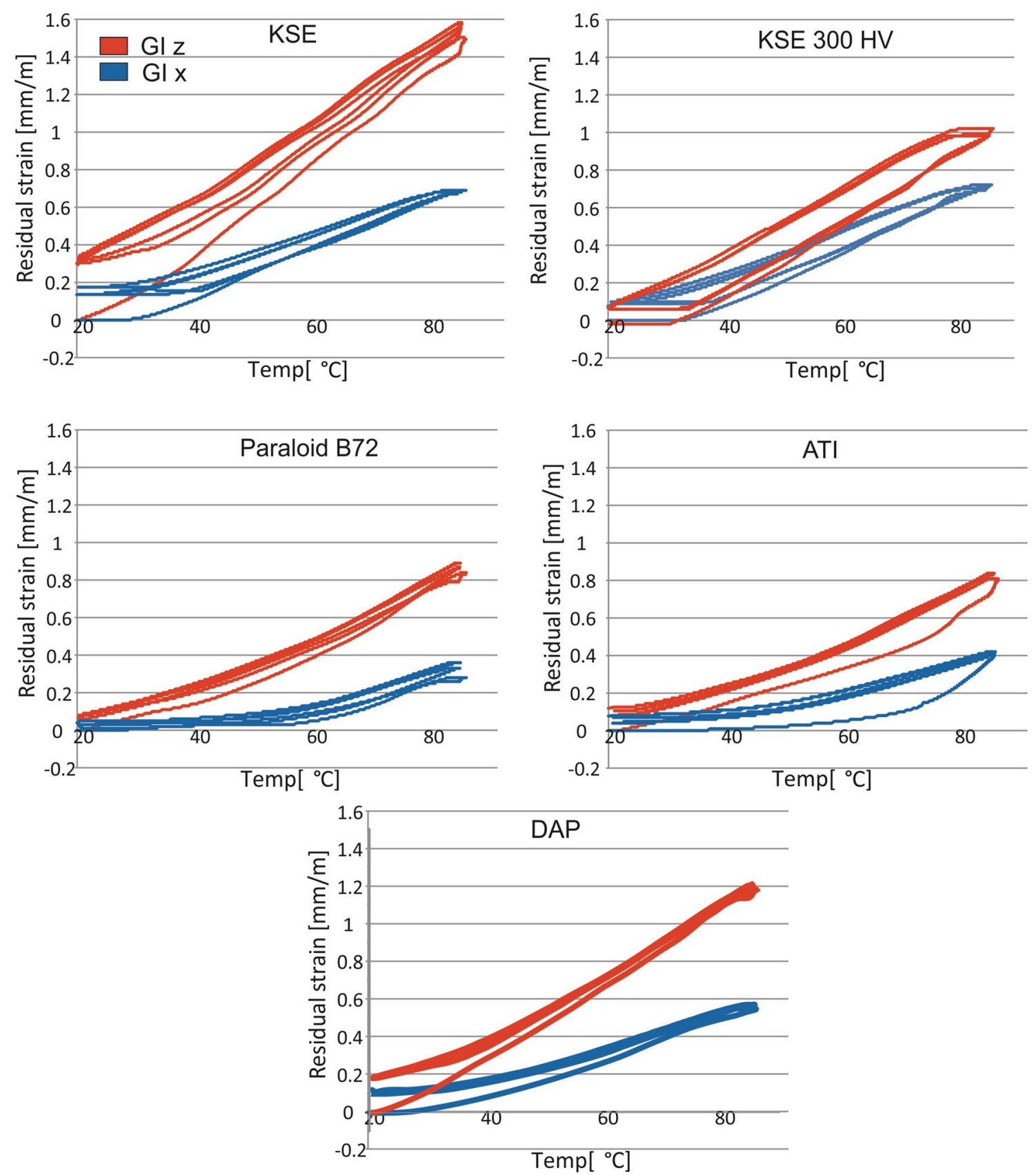

Fig. 9 Thermal dilatation $\varepsilon(\mathrm{mm} / \mathrm{m})$ shown as a loop of hysteresis for the Z-and X-direction of the Carrara Gioia, treated with the different consolidants

ATI reach about $70{ }^{\circ} \mathrm{C}$. After this temperature, the slope increases faster than before, with a smooth transition, which can be correlated to a softening of the acrylic resins. Unexpectedly, these changes in the curve slopes were registered at temperature values lower than the nominal $\mathrm{T}_{g}$ of the two resins $\left(40{ }^{\circ} \mathrm{C}\right.$ for Paraloid B72 (Vinçotte et al. 2019) and $80-85{ }^{\circ} \mathrm{C}$ for ATI50 PMMA).

The residual strain of marbles treated with Paraloid B72 was found to be sensibly increased when water was present inside the specimens, as illustrated in Fig. 10 for some exemplary conditions. While the dry cycles caused limited residual strain, the presence of water in the pores caused the Blanco Macael and Carrara Gioia to shrink and reach values of almost $-0.9 \mathrm{~mm} / \mathrm{m}$ after 5 wet cycles. This phenomenon can be attributed to a collapse of the marbleresin system (Ruedrich et al. 2002), favored by the $T_{g}$ of Paraloid B72 and by the presence of water. 
Fig. 10 Residual strain $(\mathrm{mm} / \mathrm{m})$ of Blanco Macael and Carrara Gioia in the X-and Z- directions, after treatment with Paraloid B 72, as a function of the number of heating-cooling cycles in dry ( 3 cycles) and wet (5 cycles) conditions

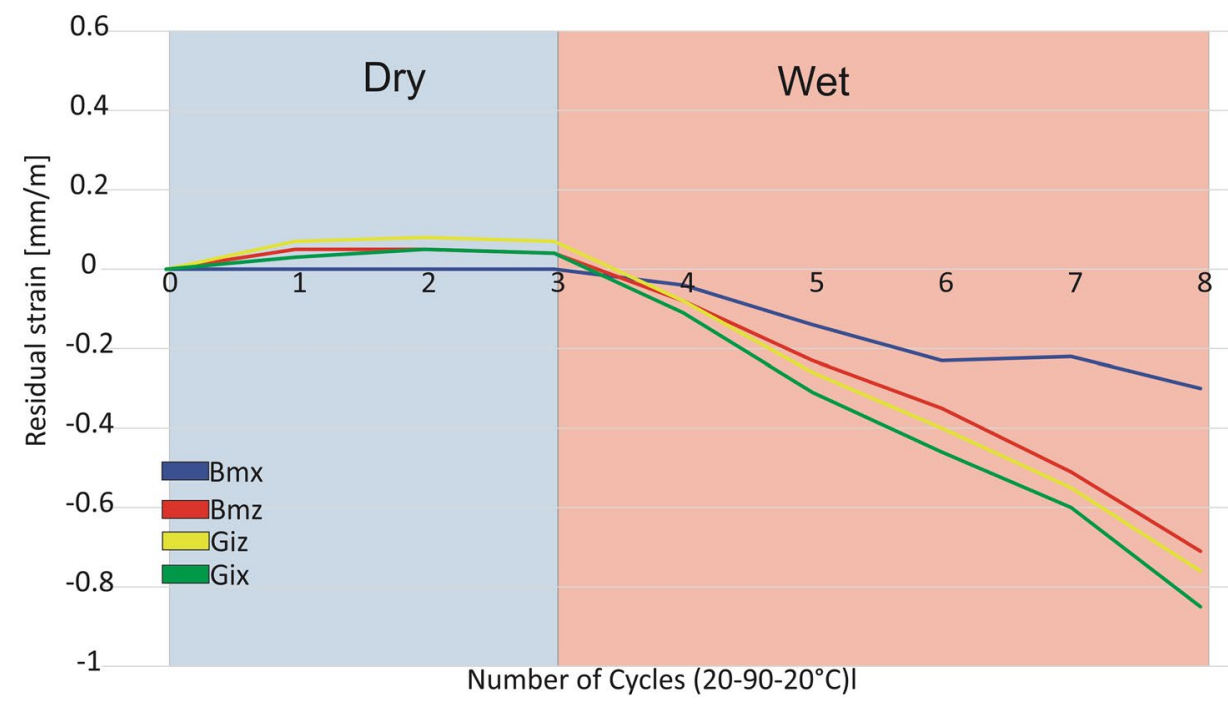

DAP-treated samples generally experienced a modest but systematic increase in the thermal expansion coefficient $\alpha$ (Table 3 ), in both directions. Nonetheless, after the heating-cooling cycles all the DAP-treated samples showed lower residual strain than the untreated reference, both in dry and wet conditions, as illustrated in Fig. 11 for all the marble
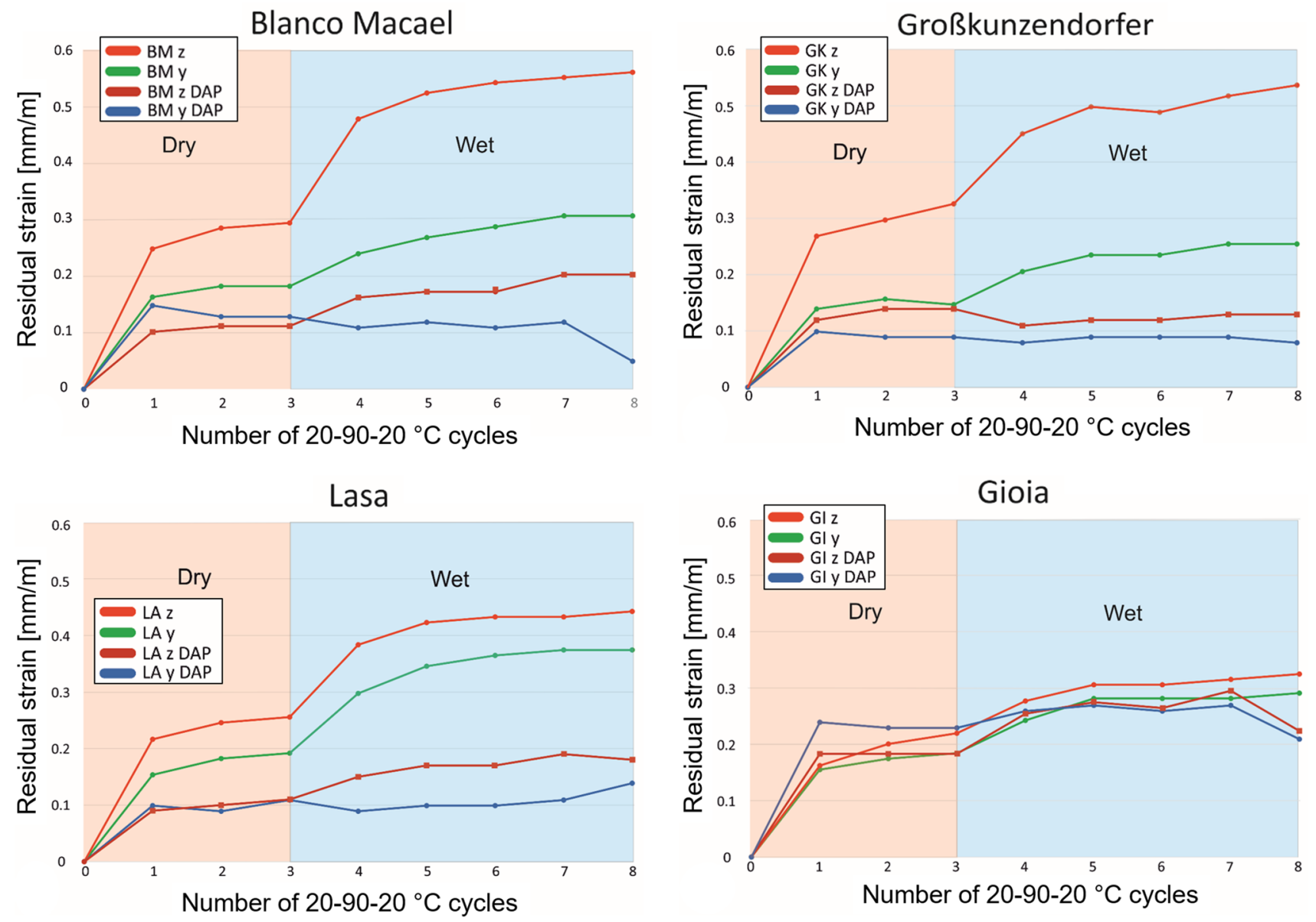

Fig. 11 Residual strain $(\mathrm{mm} / \mathrm{m})$ of the four marble varieties, untreated and DAP-treated, in the directions with the highest (red curve) and the lowest (green curve) residual strain, as a function of the number of heating-cooling cycles in dry ( 3 cycles) and wet ( 5 cycles) conditions 
varieties. Contrary to the samples treated with Paraloid B72, in no case was a progressive decrease in residual strain registered, which would be a sign of the fabric collapse. These results suggest that the DAP-treated samples have higher resistance to thermal stress. However, it should be pointed out that the DAP-treated samples had been artificially preweathered by heating at $200{ }^{\circ} \mathrm{C}$, which is expected to have partially contributed to the measured decrease in residual strain. In any case, the DAP treatment does not increase or reactivate the irreversible expansion, due to the limited occlusion of pores and microcracks by the newly formed consolidating phases (Sassoni et al. 2018a).

After consolidation and subsequent heating-cooling cycles, the cohesion of the marble specimens was tested by ultrasonic measurement for all the consolidants, as illustrated in Figs. 5 and 6.

Samples treated with both KSE 300 and KSE $300 \mathrm{HV}$ experienced a significant decrease in $V_{p}$ after the heating-cooling cycles, to such an extent that $V_{p}$ was basically reduced to the level of weathered marble and all the benefit derived from consolidation was lost.

In the case of treatments based on acrylic resin, consolidated samples showed minor decreases in $V_{p}$ after the heating-cooling cycles. This holds for both Paraloid B72 (which however caused only modest increases in $V_{p}$ after consolidation) and ATI (which improved marble cohesion back to the unweathered condition). In the case of Paraloid B72, the fact that $v_{p}$ values are maintained after the temperature cycles, even though progressive shrinking had been registered (Fig. 10), may be due to the fact that, when the glass transition temperature of Paraloid B72 is reached, the resin becomes soft and, to a certain extent, it is able to re-arrange in the intergranular fissures, thus continuing to bind the calcite grains. Further analyses would be needed to verify this hypothesis.

Samples consolidated by DAP exhibited some decrease in $V_{p}$ after the heating-cooling cycles, the magnitude of the decrease varying depending on the marble variety (Fig. 6). However, in all cases the samples subjected to the heating-cooling cycles exhibited a residual $V_{p}$ that was higher than the value before consolidation, which indicates that a mechanical benefit is still present even after accelerated thermal ageing by temperature cycles.

\section{Effects of bowing cycles}

The results of the bowing measurements are illustrated in Fig. 12. Each graph shows the bowing (in $\mathrm{mm} / \mathrm{m}$ ) as a function of the number of cycles. For each untreated sample (0), the results for the same slab after the application of DAP (I) are given. To ensure that the reduction in bowing after the DAP-treatment is not only caused by the preliminary bowing cycles (before consolidant application), one additional unweathered slab was treated with DAP and subjected to the same heating cycles II).

Almost all marble varieties showed a reduction in the bowing intensity independent of the measurement direction. Nonetheless, there are differences regarding the development of the bowing mitigation. Except for LA in the $\mathrm{z}$ direction, all the samples showed the highest benefit for the first 10 cycles, afterwards the bowing of the treated samples increased as well. BMz and $\mathrm{GKz}$ showed almost no expansion for the pre-bowed DAP-treated samples, even after 30 cycles, while their second direction showed an increase of expansion for the treated samples. For the BMy slabs, the expansion was higher than in their untreated state.

The GI and SUB slabs showed a comparable behavior: both varieties experienced a decrease in the bowing intensity after the DAP treatment, which lasts until the 30th cycle, when some increase in the bowing tendency is registered. The GKz, BMz and LAz samples showed a slightly different development. The bowing intensity did not change significantly during the 30 cycles and remained almost constant.

Comparing the unweathered samples (0) with the samples treated with DAP without preliminary bowing ("II" light green and light blue bars), it is possible to note that for all the varieties a reduction in bowing intensity is present due to DAP application. Only in the SUB sample, the bowing of the DAP-treated slab is higher than that of the untreated reference in one of the directions (y), but it is, however, lower in the other direction $(\mathrm{z})$.

\section{Conclusions}

Based on the results of the present study, aimed at evaluating the effectiveness and the thermal stability of 5 different consolidants tested on 5 different marble varieties preliminarily subjected to artificial weathering, the following conclusions can be derived:

- Treatments based on ethyl silicate (KSE 300 and KSE $300 \mathrm{HV}$ ) caused modest increases in ultrasonic velocity and modest reductions in effective porosity. While expected in the case of the traditional formulation (KSE 300), the modest consolidating effectiveness was unexpected in the case of the formulation containing a coupling agent to improve the performance on calcitic substrates. When subjected to heating-cooling cycles, samples treated by either treatment exhibited an increase in the thermal expansion coefficient and some residual strain at the end of the cycles, which may lead to minor resistance to thermal weathering after consolidation.

- Treatments based on acrylic resin exhibited different consolidating and pore-filling effects, depending on the specific product (see Figs. 13, 14, 15 and 16). Paraloid 

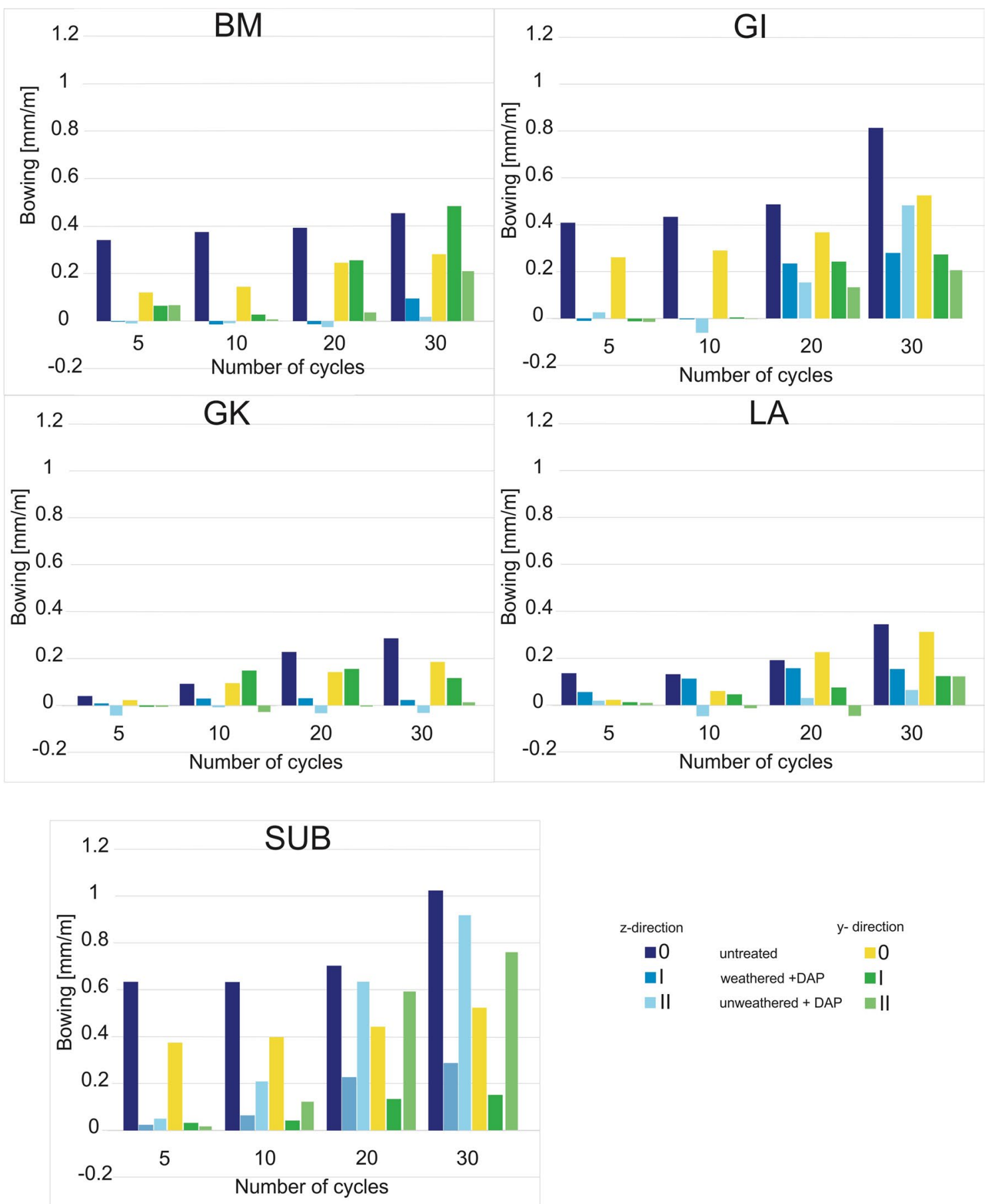

Fig. 12 Bowing $(\mathrm{mm} / \mathrm{m})$ of untreated and treated marble slabs in the $\mathrm{z}$ and $\mathrm{y} / \mathrm{x}$-direction for all five marble varieties (also including the SUB specimens) after 5, 10, 20 and 30 temperature cycles. The " 0 " data represent the evolution of the bowing behavior for the unweath-

ered sample. The "I" samples are the formerly described pre-bowed slabs after the DAP treatment, while the "II" samples are unweathered samples where the DAP solution was applied to prevent bowing

B72 caused minor alterations in the pore system and, consistently, very limited increases in ultrasonic velocity. On the contrary, samples treated by acrylic total impregnation (ATI) underwent complete pore filling by acrylic resin and significant improvements in cohesion,

so that the ultrasonic velocity was restored to the level before weathering. While ATI-treated samples apparently resisted well to heating-cooling cycles, samples impregnated with Paraloid B72 exhibited progressive 


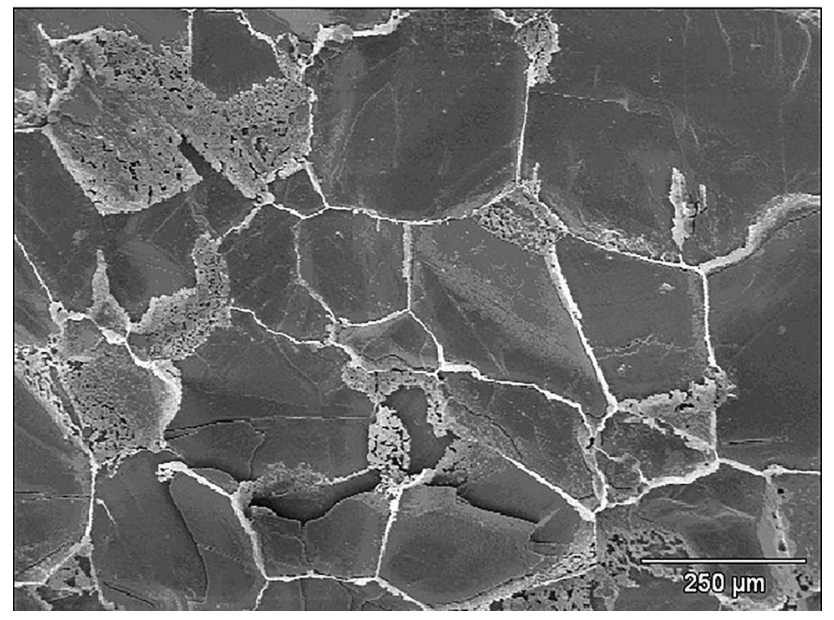

Fig. 13 PMMA filling in the pores of marble. SEM photo shows very clearly that the accessible pore space and grain boundaries are decorated with the resin

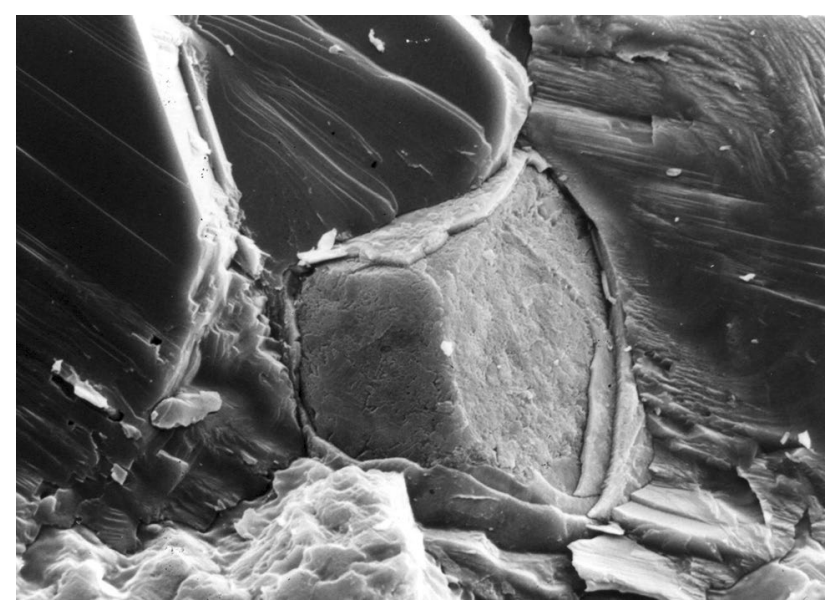

Fig. 14 Close-up of a calcite grain, which is very well coated by the impregnating agent, indicating good adherence collapse of the fabric, likely due to the low transition temperature of Paraloid B72.

- The DAP-treatment exhibited a significant ability to reduce bowing of both already bowed slabs and initially planar slabs, thus being confirmed as a promising tool to arrest and prevent bowing of thin marble slabs (see also Menningen 2020). The formation of hydroxyapatite on calcite surfaces induced by the treatment with ammonium phosphate seems to improve the cohesion of calcite crystals in marble, thereby in some cases bringing the ultrasonic velocity back to the condition before weathering (Fig. 17). When subjected to heating-cooling cycles, all the DAP-treated specimens exhibited lower residual strain than the untreated reference. 
Fig. 15 Reopening of the restored Neptune grotto to the public in 2018 (for details see Sobott et al. 2019)

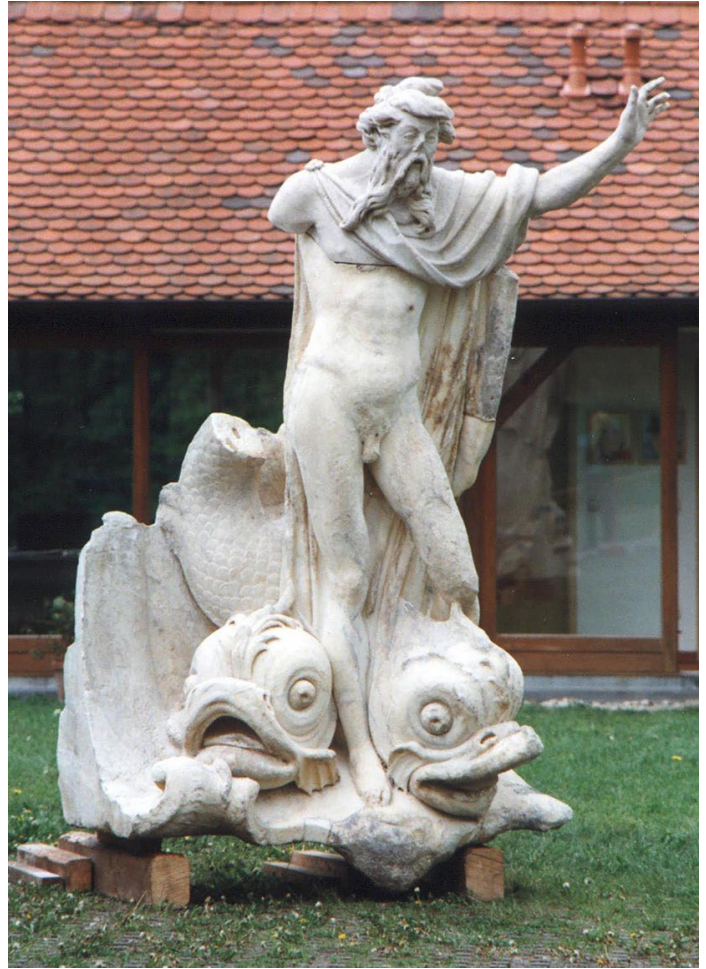

Fig. 16 The sculpture of Neptune after conservation by ATI on the premises of IbachGmbH. The ATI conservation process allows a badly damaged sculpture to return to its original site instead of final in-door storage somewhere in the cellar

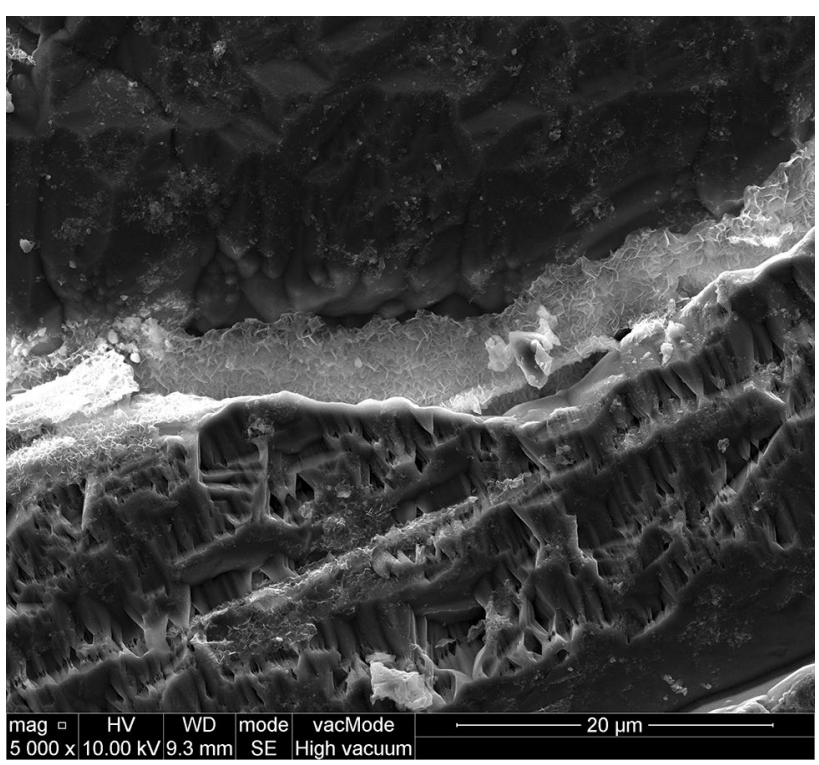

Fig. 17 SEM image clearly shows new calcium phosphates filling a microcrack among the calcite grains as a result of the DAP treatment

Acknowledgements The support of the study by the BMBF (Marmorbild FKZ: 03VP00292) is gratefully acknowledged. We also thank G. Scholz from the Jbach GmbH for performing the acrylic total impregnation of samples. Open Access funding was provided by the University of Goettingen.

Funding Open Access funding enabled and organized by Projekt DEAL. 
Open Access This article is licensed under a Creative Commons Attribution 4.0 International License, which permits use, sharing, adaptation, distribution and reproduction in any medium or format, as long as you give appropriate credit to the original author(s) and the source, provide a link to the Creative Commons licence, and indicate if changes were made. The images or other third party material in this article are included in the article's Creative Commons licence, unless indicated otherwise in a credit line to the material. If material is not included in the article's Creative Commons licence and your intended use is not permitted by statutory regulation or exceeds the permitted use, you will need to obtain permission directly from the copyright holder. To view a copy of this licence, visit http://creativecommons.org/licenses/by/4.0/.

\section{References}

Delgado JR, Grossi A (2007) Indicators and ratings for the compatibility assessment of conservation actions. J Cult Herit 8:32-43. https://doi.org/10.1016/j.culher.2006.04.007

Favaro M, Mendichi R, Ossola F, Russo U, Simon S, Tomasin P, Vigato PA (2006) Evaluation of polymers for conservation treatments of outdoor exposed stone monuments. Part I: photo-oxidative weathering. Polym Degrad Stabil 91:3083-3096

Graziani G, Sassoni E, Franzoni E, Scherer GW (2016) Hydroxyapatite coatings for marble protection: optimization of calcite covering and acid resistance. Appl Surf Sci 368:241-257. https://doi.org/ 10.1016/j.apsusc.2016.01.202

Koch A, Siegesmund S (2004) The combined effect of moisture and temperature on the anomalous expansion behaviour of marble. Environ Geol 46:3-4

Koutsokos P (1995) Stone deterioration modelling (dissolution) and surface remediation (crystallization). In: Proceedings of the 6th Workshop, Eurocare-Euromarble, Suzdal 1995, Forschungsbericht 16/1995, Bayerisches Landesamt für Denkmalpflege-Zentrallabor, Muenchen, pp 19

Leiss B, Ullemeyer K (1999) Texture characterisation of carbonate rocks and some implications for the modeling of physical anisotropies, derived from idealized tex- ture types. $\mathrm{Z}$ der Deutschen Geologischen Ges 150(2):259-274

Menningen J (2020) Ultrasonic tomography for the characterization of the weathering state of marble: a systematic study about influencing parameters. Unpublished $\mathrm{PhD}$ thesis, University Göttingen, pp 232

Menningen J, Siegesmund S, Tweeton D, Träupmann M (2018) Ultrasonic tomography: non-destructive evaluation of the weathering state on a marble obelisk, considering the effects of structural properties. Environ Earth Sci 77(17):1338

Menningen J, Siegesmund S, Krompholz R, Rieffel Y (2020) The marble sculptures of General Bülow and Scharnhorst in Berlin: comparative, non-destructive analysis of the weathering state after 12 years of exposure. Environ Earth Sci 79:1-23

Naidu S, Scherer GW (2014) Nucleation, growth and evolution of calcium phosphate films on calcite. J Colloid Interface Sci 435:128-137

Naidu S, Sassoni E, Scherer GW (2011) New treatment for corrosionresistant coatings for marble and consolidation of limestone. In: Stefanaggi M, Vergès-Belmin V (eds) Jardins de Pierres: conservation of stone in parks, gardens and cemeteries. XL Print, Paris, pp 289-294

Ruedrich J, Weiss T, Siegesmund S (2002) Thermal behaviour of weathered and consolidated marbles. Geol Soc Lond Spec Publ 205:255-271
Ruedrich J, Knell C, Enseleit J, Rieffel Y, Siegesmund S (2013) Stability assessment of marble statuaries of the Schlossbrücke (Berlin, Germany) based on rock strength measurements and ultrasonic wave velocities. Environ Earth Sci 69(4):1451-1469

Sassoni E (2018) Hydroxyapatite and other calcium phosphates for the conservation of cultural heritage: a review. Materials 11:557. https://doi.org/10.3390/ma11040557

Sassoni E, Franzoni E (2020) Lime and cement mortar consolidation by ammonium phosphate. Constr Build Mater 245:118409. https:// doi.org/10.1016/j.conbuildmat.2020.118409

Sassoni E, Naidu S, Scherer GW (2011) The use of hydroxyapatite as a new inorganic consolidant for damaged carbonate stones. J Cult Herit 12:346-355. https://doi.org/10.1016/j.culher.2011. 02.005

Sassoni E, Franzoni E, Pigino B, Scherer GW, Naidu S (2013) Consolidation of calcareous and siliceous sandstones by hydroxyapatite: comparison with a TEOS-based consolidant. J Cult Herit 14S:e103-e108. https://doi.org/10.1016/j.culher.2012.11.029

Sassoni E, Graziani G, Franzoni E (2015) Repair of sugaring marble by ammonium phosphate: comparison with ethyl silicate and ammonium oxalate and pilot application to historic artifact. Mater Des 88:1145-1157. https://doi.org/10.1016/j.matdes.2015.09.101

Sassoni E, Graziani G, Ridolfi G, Bignozzi MC, Franzoni E (2017) Thermal behavior of Carrara marble after consolidation by ammonium phosphate, ammonium oxalate and ethyl silicate. Mater Des 120:345-353. https://doi.org/10.1016/j.matdes.2017.02.040

Sassoni E, Andreotti S, Scherer GW, Franzoni E, Siegesmund S (2018a) Bowing of marble slabs: can the phenomenon be arrested and prevented by inorganic treatments? Environ Earth Sci 77(10):4077

Sassoni E, Graziani G, Franzoni E, Scherer GW (2018b) Calcium phosphate coatings for marble conservation: influence of ethanol and isopropanol addition to the precipitation medium on the coating microstructure and performance. Corros Sci 136:255-267. https:// doi.org/10.1016/j.corsci.2018.03.019

Sassoni E, Graziani G, Franzoni E, Scherer GW (2018c) Conversion of calcium sulfate dihydrate into calcium phosphates as a route for conservation of gypsum stuccoes and sulfated marble. Constr Build Mater 170:290-301. https://doi.org/10.1016/j.conbuildmat. 2018.03.075

Scherer GW, Wheeler GS (2009) Silicate consolidants for stone. Key Eng Mater 391:1-25. https://doi.org/10.4028/0-87849-365-4.1

Siegesmund S, Ullemeyer K, Weiss T, Tschegg EK (2000) Physical weathering of marbles caused by anisotropic thermal expansion. Int J Earth Sci 89(1):170-182

Siegesmund S, Ruedrich J, Koch A (2008) Marble bowing: comparative studies of three different public building facades. Env Geol 56(3-4):473-494

Simon S (2001) Zur Verwitterung und Konservierung kristallinen Marmors: Untersuchungen zu physiko-mechanischen Gesteinskennwerten, zur Oberflächenchemie von Calcit und zur Anpassung und Überprüfung von Gesteinsschutzmitteln. Dissertation, München.

Snethlage R (2008) Leitfaden Steinkonservierung.: Planung von Untersuchungen und Maßnahmen zur Erhaltung von Denkmälern aus Naturstein, 3rd edn. Fraunhofer IRB, Stuttgart

Sobott R, Scholz G, Ibach HW (2019) AVT weiterentwickelt. Naturstein 02:45-47

Vinçotte A, Beauvoit A, Boyard N, Guilminot E (2019) Effect of solvent on PARALOID @ B72 and B44 acrylic resins used as adhesives in conservation. Herit Sci 7:42. https://doi.org/10.1186/ s40494-019-0283-9

Weiss T, Rasolofosaon PNJ, Siegesmund S (2002) Ultrasonic wave velocities as a diagnostic tool for the quality assessment of marble. In: Siegesmund S, Weiss T, Vollbrecht A (eds) Natural stone, weathering phenomena, conservation strategies and case studies, 
vol 205. Geological Society, Special Publications, London, pp $149-164$

Wheeler GS (2005) Alkoxysilanes and the consolidation of stone (research in conservation). The Getty Conservation Institute, Los Angeles

Wihr R (1995) Fünfzehn Jahre Acrylharzvolltränkung in Bayern. Arbeitsblätter Stein 9:32-40
Publisher's Note Springer Nature remains neutral with regard to jurisdictional claims in published maps and institutional affiliations. 